\title{
Development of new functional fermented product: mulberry-whey beverage
}

\author{
Tamer S. AbdulAlim, ' Abeer F. Zayan,' Pedro H. Campelo, ${ }^{4}$ Amr M. Bakry $2,3, *$ \\ 'Dairy Science and Technology Research Department, Food Technology Research Institute, Agriculture Research Center, Giza I26I9, Egypt. \\ ${ }^{2}$ College of Food Science and Technology and MOE Key Laboratory of Environment Correlative Dietology, Huazhong Agricultural University, Wuhan 430070, \\ China
}

${ }^{3}$ Department of Dairy Science, Faculty of Agriculture, Suez Canal University, Ismailia 4I 522, Egypt

${ }^{4}$ Faculty of Agrarian Science, Federal University of Amazonas, Manaus, AM, Brazil

*Correspondence: Amr M. Bakry, ${ }^{2}$ College of Food Science and Technology and MOE Key Laboratory of Environment Correlative Dietology, Huazhong Agricultural University, Wuhan, China, and ${ }^{3}$ Department of Dairy Science, Faculty of Agriculture, Suez Canal University, Ismailia, Egypt,Tel +86-I880059|794, Email amr.bakry@agr.suez.edu.eg, bakryamr@ymail.com

Received: October 4, 2018 | Published: October 15, 2018

Copyright@ 2018 AbdulAlim et al. This is an open access article distributed under the terms of the Creative Commons Attribution License, which permits unrestricted use, distribution, and reproduction in any medium, provided the original author and source are credited.

\begin{abstract}
This study was conducted to produce and evaluate probiotic whey beverage during cold storage for 21 days. Five mixes of probiotic drinks were formulated for sweet whey (SW) and black mulberry (BM) juice. Physiochemical and microbiological properties as well as organoleptic evaluation were determined during cold storage at $4 \pm 1^{\circ} \mathrm{C}$. The obtained results indicated that acidity of beverage treatments was gradually increased during cold storage. Meanwhile, the $\mathrm{pH}$ values and total phenolic contents were decreased gradually during cold storage. On the other hand, the antioxidant activity was increased by
\end{abstract}

increasing the percentage of black mulberry juice; however, it was decreased during cold storage. Results clearly indicated that the viability of $L$. rhamnosus GG \& Bifidobacterium animalis ssp. lactis Bb-12 remained high up to 14 days then started to decline. Sensory properties of all samples were accepted while SWBM3 (25\% whey with 75\% BM juice) gained the highest organoleptic scores. Our results showed a high potential to produce and develop a new functional fermented whey product.

Keywords: sweet whey, black mulberry, probiotic

\section{Introduction}

In recent decades, the market for functional fermented milk components is continually increasing especially whey. As sub-product of the cheese industry, whey is widely used as food ingredients due to their nutritional composition ( $93 \%$ water, $5 \%$ lactose, $0.8 \%$ proteins, $9 \%$ minerals, and $0.36 \%$ fat) and the large volumes produced. Wheybased lactic beverages are a perfect way to reuse the liquid whey due to its high nutritional value, low cost and sensory value. ${ }^{1-3}$ However, whey-based lactic beverages represent a part of non-traditional dairy products that need chemical, physical, and sensory properties for product development and quality control. ${ }^{4}$ Several lactic acid bacteria (LAB) and yeast may be employed in lactic beverages production. Hence, lactic beverages may be taken into account as an important driver for the delivery of probiotic micro-organisms in the human gastro intestine. 5,6 Currently, many products are being developed that utilizing mix of whey, milk, fruit juice, probiotic bacteria and/ or yeast. ${ }^{4,-9} \mathrm{LAB}$ has been extensively used in a wide range of the production of dairy fermented products. It could hydrolyze milk proteins; moreover, some of them can decompose $\beta$-lactoglobulin (BLG) "allergens" during life cycle in whey and milk. ${ }^{10,11}$ Pescuma et al. ${ }^{12,13}$ reported that the strains of Lactobacilus acidophilus, $L$. paracasei, and Bifidobacterium have the ability to analyse the BLG allergenic epitopes in vitro.

Mulberry (Morus alba L. or Folium mori) is the fruit of the mulberry tree belonging to the genus Morus of the Moreaceae family. This fruit is cultivated in Africa, Asia, Europe, North and South America. It is famous in China for medical treatment due to its high content of nutritive compounds such as vitamins, amino acids, minerals, phenolic acids, anthocyanins "cyanidin-3-glucoside and cyanidin-3rutinoside" and flavonols. ${ }^{14-17}$ In addition to their numerous functional properties including anticancer, antidiabetic, antioxidant, antiinflammatory, and anti-aging, also decreases the risk of coronary heart disease obesity and diabetes. ${ }^{15}$ The antioxidant properties of phenolic compounds have the ability to act as metal chelators, proton donors and reducing agents. ${ }^{18}$ Mulberries contain alkaloids that activate macrophages which are white blood cells that stimulate the immune system, putting it on high active alert against health threats. ${ }^{19}$ As predominant polyphenols, anthocyanins up to $\sim 3000 \mathrm{mg} / \mathrm{kg} \mathrm{FW}$ are found in mulberry fruits, which is one example of important naturally derived antioxidants. These fruits have much higher anthocyanins content than blackcurrant, redcurrant, blueberry, and blackberry. ${ }^{20}$ Although the abovementioned health benefits and antioxidant properties of mulberry fruits, fresh mulberry are soft and perishable fruit that possess a very short shelf-life, moreover, it has a low acidity. Hence, the aim of this study was to investigate the possibility of introducing functional whey-mulberry beverages in order to enhance the shelf-life, nutritional and organoleptic qualities. Influence of addition of mulberry fruits with different ratio on physiochemical, microbiological and sensorial characteristics of sweet whey (SW) was discussed during storage. Results of this investigation could be an indicator for the development of health promoting food ingredients. 


\section{Materials and methods}

\section{Materials}

Fresh whey from manufacturing of Ras-cheese was provided by the agricultural secondary school (Shibin El-Kom, Menoufia, Egypt). The chemical composition of whey consists mainly from total solids $(6.3 \pm$ $0.026 \mathrm{~g} / 100 \mathrm{~g})$, protein $(0.8 \pm 0.015 \mathrm{~g} / 100 \mathrm{~g})$, fat $(0.5 \pm 0.115 \mathrm{~g} / 100$ g) and lactose $(4.5 \pm 0.104 \mathrm{~g} / 100 \mathrm{~g})$. The whey was then subjected to heat treatment at $68^{\circ} \mathrm{C}$ for $15 \mathrm{~min}$ then stored in plastic bottles at $4^{\circ} \mathrm{C}$ after cooling in an ice bath and frozen for further analysis. Black mulberry (BM, Morus alba L.), skim milk powder and sugar were purchased from a local market located in Menoufia, Egypt. The fresh BM kept at $4^{\circ} \mathrm{C}$ until use. The starter culture strains $L$. delbrueckii subsp. bulgaricus, Streptococcus thermophilus and L. rhamnosus GG used in this work were obtained from Valio Ltd. (Helsinki, Finland) Bifidobacterium animalis ssp. lactis $\mathrm{Bb}-12{ }^{\circledR}$ was supplied by $\mathrm{Chr}$. Hansen Inc. (Hoersholm, Denmark). All strains were kept as frozen stocks in $40 \%$ glycerol at $-20^{\circ} \mathrm{C}$. Gallic acid, folin-Ciocalteu reagent and 1,1-diphenyl-2-picrylhydrazyl (DPPH) were purchased from Sigmae-Aldrich Co. (St. Louis, MO, USA). Ringer's solution was obtained from Oxoid Ltd. (Basingstoke, Hampshire, UK). MRS and M17 agar were purchased from Merck KGaA (Darmstadt, Germany). Other chemicals ( $\mathrm{NaOH}, \mathrm{HCl}, \mathrm{NaOH}, \mathrm{Na}_{2} \mathrm{CO}_{3}$, methanol, and ethanol) were purchased from SinoPharm Ltd. (Shanghai, China).

\section{Preparation of cultures}

A pre-starter culture (PSC) was dissolved and diluted in $50 \mathrm{~mL}$ skimmed milk before sterilization at $121^{\circ} \mathrm{C}$ for $10 \mathrm{~min}$, and then cooled to $5^{\circ} \mathrm{C}$. The pre-cultures were warmed at $42^{\circ} \mathrm{C}$ for $20 \mathrm{~min}$ before inoculation. Starter cultures were prepared by transferring PSC in SW before experimental use; PSC (2\% v/v) was used as inocula. Fermentations were performed in sealed bottles containing $300 \mathrm{~mL}$ of SW and incubated at $37^{\circ} \mathrm{C}$ until the $\mathrm{pH}$ value reached $\square 4.5$, and the $\mathrm{pH}$ was then adjusted to 5.5 with $5 \mathrm{~N} \mathrm{NaOH}$. All treatments of SW were subjected to heat treatment at $60^{\circ} \mathrm{C}$ for $10 \mathrm{~min}$ to stop the fermentation process by starter culture.

B. lactis $\mathrm{Bb}-12$ and L. rhamnosus $\mathrm{GG}$ probiotic cultures were grown initially for $48 \mathrm{~h}$ followed by sub-culturing and incubating for a further $17 \mathrm{~h}$. The culture was harvested after centrifugation at $3200 \times \mathrm{g}$, for $10 \mathrm{~min}$ at $4^{\circ} \mathrm{C}$. The pellets were washed twice in one-quarter-strength Ringer's solution and concentrated 10 -fold in the same diluent. A $1 \%$ inoculum of probiotic culture was distributed into the $\mathrm{BM}$ juices to get a final concentration of approximately $10^{8} \mathrm{CFU} \mathrm{\textrm {mL } ^ { - 1 }}$.

\section{Preparation of mulberry-whey beverages}

Five different whey based beverages (WBB) were prepared without BM (SW) and with 25\% BM (SWBM1), 50\% BM (SWBM2), 75\% BM (SWBM3) and 100\% BM (SWBM4), respectively (Figure 1), considering the volume of inoculum and sugar. Sugar was added at a concentration of $15 \%(\mathrm{w} / \mathrm{v})$ of the probiotic whey based beverages. The resulting mixtures were formulated under aseptic condition then stored at $4^{\circ} \mathrm{C}$ for 21 days.

\section{Microbiological analysis}

At appropriate intervals over several days/weeks depending on the specific strain, viable cell counts were recorded before cold storage. Serial dilutions were subsequently performed and bacteria were counted by applying the standard plate count method. The counts of Lactobacillus bulgaricus were estimated by culture in MRS agar under anaerobic incubation at $37^{\circ} \mathrm{C}$ for 2 days. M17 agar was used for the enumeration of $S$. thermophilus. The petri dishes were incubated aerobically for 2 days at $37^{\circ} \mathrm{C} .{ }^{21}$ Enumerations of L. rhamnosus GG and bifidobacteria were carried out on MRS agar adjusted to $\mathrm{pH} 5.4$ with glacial acetic acid under aerobic incubation at $37^{\circ} \mathrm{C}$ for $48 \mathrm{~h}$. The selectivity of the growth conditions was confirmed by microscope appearance of the cells from single colonies.

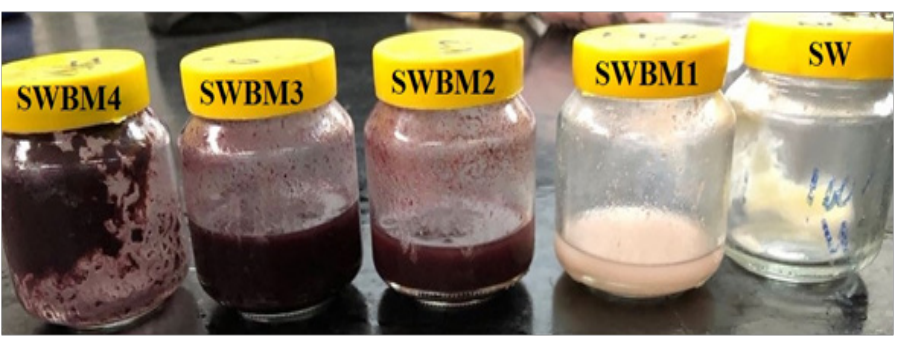

Figure I The samples of five different whey based beverages without BM (SW) and with 25\% BM (SWBMI), 50\% BM (SWBM2), 75\% BM (SWBM3), and $100 \%$ BM (SWBM4).

\section{Physiochemical analysis}

\section{Determination of $\mathrm{pH}$ values and titratable acidity}

The $\mathrm{pH}$ values of raw materials (BM and whey) and samples were determined using a digital $\mathrm{pH}$ meter (HI8519, Hanna Instruments, Italy) with a temperature compensator. The titratable acidity was determined according to the Association of Official Analytical Chemists. ${ }^{22}$

\section{Determination of total solids, soluble solids, protein, fat, lactose and ash content}

The total solids content was measured by the oven drying method at $105^{\circ} \mathrm{C}$ up to a constant weight. ${ }^{22}$ The concentrate was characterized for lactose, ash and total soluble solids, according to the A.O.A.C. ${ }^{23}$ Protein content was determined by the macro-Kjeldahl ${ }^{24}$ and fat by the Gerber method. ${ }^{25}$

\section{Determination of total phenolics}

The total phenolic content (TPC) of samples was determined by using Folin-Ciocalteu method according to López-García et al. ${ }^{26}$, with some modifications. Briefly, $0.1 \mathrm{~mL}$ of sample was mixed with $0.75 \mathrm{~mL}$ of diluted Folin-Ciocalteu reagent (10-fold dilution with distilled water). After $5 \mathrm{~min}$ of incubation at room temperature, $0.75 \mathrm{~mL}$ of $2 \%$ sodium carbonate solution was added to the mixture. Then, the mixture was incubated for $15 \mathrm{~min}$ at room temperature and absorbance was measured at $760 \mathrm{~nm}$. The results were indicated as milligram of gallic acid equivalent per $100 \mathrm{~mL}$ of sample. Calibration curve was carried out with gallic acid aqueous solutions $(8-80 \mu \mathrm{g} / \mathrm{mL})$.

\section{Determination of antioxidant activity}

The antioxidant activity of whey beverages was determined by DPPH assay. Briefly, $2 \mathrm{~mL}$ of the whey beverages in clean and labeled test tubes dissolved in methanol was mixed with $2 \mathrm{~mL}$ of $0.2 \mathrm{mM} \mathrm{DPPH}$. The mixture was then homogenized and left at room temperature in the dark for $30 \mathrm{~min}$. The absorbance by using a UV-VIS spectrophotometer (6705B0, Jenway, Norfolk, USA) was measured at $517 \mathrm{~nm}$ and methanol used as a blank. The DPPH radical scavenging activity was calculated as follows:

DPPH scavenging activity $(\%)=[(A-B) / A] \times 100$
Submit your Article | www.ologypress.com/submit-article PP ${ }_{\text {Press }}^{\text {Ology } f \text { in } y \text { rifio }}$ 
Here, $A$ is the absorbance of the DPPH solution without sample and $B$ is the absorbance of solution containing sample.

\section{Determination of anthocyanins}

By the $\mathrm{pH}$ differential method, the total anthocyanins content of all beverages were measured according to Klopotek et al. ${ }^{27}$ using a UV-VIS spectrophotometer (6705B0, Jenway, Norfolk, USA). The procedure involved extraction of the anthocyanin with ethanol and $\mathrm{HCl}$ instead of methanol and formic acid, respectively. The absorbance of the beverages was measured at 510 and $710 \mathrm{~nm}$ using buffer solutions ( $\mathrm{pH} 1.0$ and 4.5). The total anthocyanins content were calculated as follows:

$$
A=\left(A_{510}-A_{710}\right)_{p H 1.0}-\left(A_{510}-A_{710}\right)_{p H 4.5}
$$

The results were expressed as mg malvidin-3-glucoside/100 $\mathrm{mL}(\%)$.

\section{Sensory evaluation}

Sensory evaluation was conducted according to Dubost et al. ${ }^{28}$ with several modifications. A group of ten trained panelists aged between 25 and 60 years old from the Food Technology Research Institute (CFTRI) were included to perform the sensory evaluations. Panelists were asked to evaluate the samples for acceptability of flavor, sweetens, color and appearance via scoring the samples from 1 to 10 . All panelists were selected based on willingness to consume milk beverages with no negative allergic reactions. Samples were presented to the panelists in a plastic coded cup $(50 \mathrm{~mL})$ and the presentation order was randomized for each panelist. Water cups were provided between samples to cleanse the palate.

\section{Statistical analysis}

Statistical analysis of the data was carried out by ANOVA using SAS (Statistical Analysis System) software version 9.1.3. The significant differences among means were assessed by Duncan's multiple range test at $p<0.05$.

\section{Results and discussion}

\section{Chemical composition of raw materials}

The chemical composition of the SW and BM (\%) are shown in Table 1. The results showed that the moisture content of BM was $87.40 \%$ and SW was $93.70 \%$. Ash content was $3.48 \%$ and $0.5 \%$ in $\mathrm{BM}$ and SW, while fat content was $1.25 \%$ and $0.5 \%$ in $\mathrm{BM}$ and SW, respectively. Further, the protein content of BM was $1.23 \%$, while in SW was $0.8 \%$ (Table 1). On the other hand, total soluble solids, total solids and acidity were $8.23 \%, 12.60 \%$ and $0.65 \%$ in BM, while $5.70 \%, 6.30 \%$ and $0.32 \%$ in SW, respectively. Therefore, it could be noticed that $\mathrm{BM}$ recommended for processing due to its relatively

high total soluble solids (TSS) and total solids (TS) contents, and SW is employed as a functional food ingredient because of its nutritional value.

\section{$\mathrm{pH}$ values and acidity}

The $\mathrm{pH}$ value of the whey beverage decreased significantly $(P<0.05)$ during cold storage after 21 days (Figure 2), due to the persistent metabolic activity of LAB to produce lactic acid and galactose by consumption of lactose during cold storage. Also, total acidity was increased gradually by increasing mulberry percentage at zero time (Fresh) of storage. The fermented SWBM1, SWBM2, SWBM3, and SWBM4 produced a higher amount of lactic acid compared with that prepared without BM (SW). As shown in Figure 2, the total acidity basically ranked in order SWBM4 $>$ SWBM3 $>$ SWBM2 $>$ SWBM1
$>$ SW after 21 days. It's probably due to the increase of anthocyanin content.

Table I Chemical composition of BM and SW

\begin{tabular}{lll}
\hline Content & BM & SW \\
\hline Moisture (\%) & 87.40 & 93.70 \\
Total solids (\%) & 12.60 & 06.30 \\
Total soluble solids (\%) & 08.23 & 05.70 \\
Protein (\%) & 01.23 & 00.80 \\
Fat (\%) & 01.25 & 00.50 \\
Lactose (\%) & ND & 04.50 \\
Ash (\%) & 03.48 & 00.50 \\
Titratable acidity (\%) & 00.65 & 00.32 \\
pH values (\%) & 03.70 & 05.30 \\
Anthocyanin (\%) & 65.40 & ND \\
\hline
\end{tabular}

*ND: Not detected

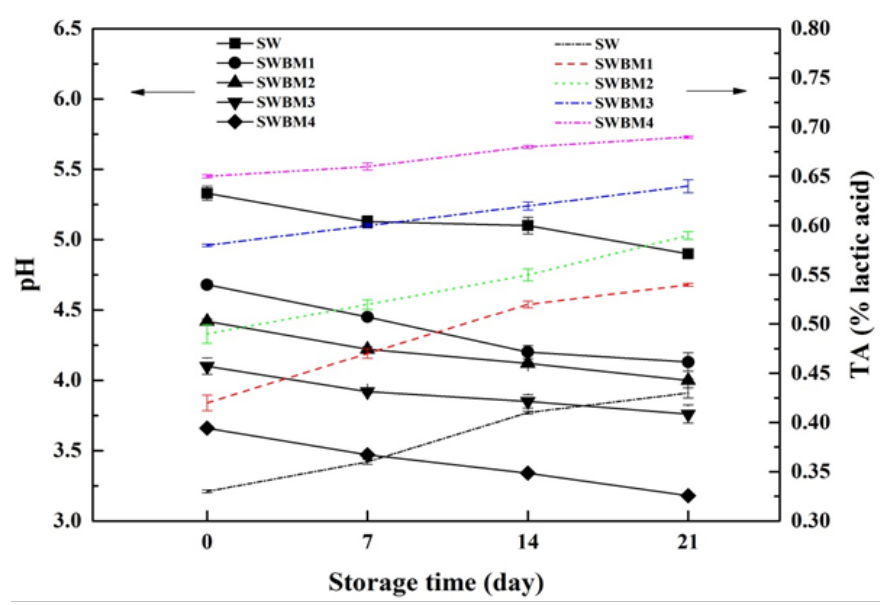

Figure 2 The $\mathrm{pH}$ values and titratable acidity of black mulberry whey beverages during cold storage at $4 \pm 1^{\circ} \mathrm{C}$.

\section{Viability of probiotic microorganisms in whey- mulberry beverages}

There is no doubt that probiotic strains selected for commercial use keep their viability and functional activity throughout the shelf-life of whey beverage products. On this base, the commercial strain $L$. rhamnosus GG was identified as a versatile culture because of their capacity to remain viable in the low $\mathrm{pH}$ juice matrix at commercially acceptable levels for at least 12 weeks. ${ }^{29}$ Data in Table 2 show a decrease in cell count was observed for all strains after 21 days. The viable cell count of $L$. rhamnosus GG was increased through the second week of storage for all treatments, then slightly decreased at end of storage. B. lactis $\mathrm{Bb}-12$ is recognized as being more robust when confronted with hostile conditions. ${ }^{30} \mathrm{~B}$. lactis $\mathrm{Bb}-12$ showed no significant decrease in viability over three weeks of storage in juice and the numbers remained above $10^{6} \mathrm{CFU} \mathrm{mL}^{-1}$ at different $\mathrm{pH}$ degrees. Notably, survival of B. lactis Bb-12 \& L. rhamnosus GG may be due to phenolic compounds that act as shell against oxygen, besides nutrients in whey. These results are in agreement with Matsumoto et al. ${ }^{31}$ and Sheehan et al. ${ }^{29}$ 
Table 2 Viability (log CFU ml-1) of L. rhamnosus GG in probiotic black mulberry whey beverages during cold storage at $4 \pm I^{\circ} \mathrm{C}$

\begin{tabular}{lllll}
\hline \multirow{2}{*}{ Treatments } & \multicolumn{4}{l}{ L. rhamnosus GG } \\
\cline { 2 - 5 } & Fresh & $\mathbf{7}$ days & $\mathbf{1 4}$ days & $\mathbf{2 1}$ days \\
\hline SW & $7.56^{\mathrm{ab}}$ & $8.06^{\mathrm{a}}$ & $7.96^{\mathrm{a}}$ & $7.50^{\mathrm{a}}$ \\
SWBMI & $7.73^{\mathrm{ab}}$ & $8.03^{\mathrm{a}}$ & $7.74^{\mathrm{a}}$ & $7.74^{\mathrm{a}}$ \\
SWBM2 & $8.01^{\mathrm{a}}$ & $7.90^{\mathrm{a}}$ & $7.85^{\mathrm{a}}$ & $7.64^{\mathrm{a}}$ \\
SWBM3 & $8.10^{\mathrm{a}}$ & $8.01^{\mathrm{a}}$ & $7.78^{\mathrm{a}}$ & $7.88^{\mathrm{a}}$ \\
SWBM4 & $8.00^{\mathrm{a}}$ & $7.90^{\mathrm{a}}$ & $7.66^{\mathrm{a}}$ & $6.68^{\mathrm{a}}$ \\
\hline
\end{tabular}

Values with different letters in the same column are significant different at $P<0.05$

\section{Anthocyanin content}

The effect of adding different ratios of BM juice on anthocyanin content of whey beverages during cold storage is illustrated in Table 3 . The total anthocyanin of mulberry whey beverages was increased by increasing the addition ratio of mulberry juices at zero time (Fresh) of storage. On the other hand, data showed a slight decrease in anthocyanin contents during cold storage. This slight decrease could be due to the influence of fermentation condition that affects the decay of anthocyanin. This result is in agreement with Viljanen et al. ${ }^{32}$ As shown in Table 3, SWBM4 had the highest degradation level (about 17\%) during cold storage, which contains $100 \%$ BM, but with reducing BM level in all treatments, degradation level reduced by about $5 \%$. These results explain that ascorbic acid correlated with anthocyanin decay level. Our data is in agreement with Chung et al. ${ }^{33}$ who reported that vitamin $\mathrm{C}$ (L-ascorbic acid) is known to accelerate anthocyanin degradation. Castañeda-Ovando et al. ${ }^{34}$ reported that whey protein could improve anthocyanin stability by interacting with either the anthocyanin itself or with the ascorbic acid, this phenomenon is known as copigmentation.

Table 3 The effect of adding different ratio of black mulberry juice on anthocyanin content of whey beverages during cold storage at $4 \pm 1^{\circ} \mathrm{C}$

\begin{tabular}{lllll}
\hline \multirow{2}{*}{ Treatments } & \multicolumn{4}{l}{ Anthocyanin $(\mathbf{m g} / \mathbf{~ 0 0 g})$} \\
\cline { 2 - 5 } & \multicolumn{1}{l}{ Fresh } & $\mathbf{7}$ days & $\mathbf{1 4}$ days & $\mathbf{2 1}$ days \\
\hline SW & - & - & - & - \\
SWBMI & $12.1^{\mathrm{d}}$ & $10.23^{\mathrm{d}}$ & $9.65^{\mathrm{d}}$ & $7.59^{\mathrm{d}}$ \\
SWBM2 & $23.30^{\mathrm{c}}$ & $25.33^{\mathrm{c}}$ & $20.30^{\mathrm{c}}$ & $17.48^{\mathrm{c}}$ \\
SWBM3 & $36.73^{\mathrm{b}}$ & $30.70^{\mathrm{b}}$ & $25.45^{\mathrm{b}}$ & $21.26^{\mathrm{b}}$ \\
SWBM4 & $45.22^{\mathrm{a}}$ & $40.36^{\mathrm{a}}$ & $33.29^{\mathrm{a}}$ & $28.85^{\mathrm{a}}$ \\
\hline
\end{tabular}

Values with different letters in the same column are significant different at $P<0.05$

\section{Total phenolic content}

The changes in TPC (equivalent $\mathrm{mg}$ gallic acid /100 mL) of BM whey beverages during cold storage at $4 \pm 1^{\circ} \mathrm{C}$ are shown in Figure 3. TPC of whey beverages prepared with different ratios of BM juices was increased by increasing the concentration of BM juices. Data revealed that TPC was decreased in all samples during storage. For example, SWBM4 showed the highest content of TPC $(17.90 \mathrm{mg} / 100 \mathrm{~mL})$ at the end of the cold storage. While, SW and SWBM1 showed the lowest content of TPC $(2.00 \& 4.00 \mathrm{mg} / 100 \mathrm{~mL}$, respectively). Our results are in agreement with Sagdic et al. ${ }^{35}$

\section{Antioxidant activity}

The effect of adding different ratios of BM juice on DPPH-radical scavenging activity (RSA) of whey beverages during cold storage at $4 \pm 1^{\circ} \mathrm{C}$ were illustrated in Figure 4. DPPH radical scavenging activity (RSA) of all treatments (SWBM1, SWBM2, SWBM3, and SWBM4) has higher antioxidant activity than control (SW), and this was directly proportional to the percentage of added juice. DPPH radical scavenging activities of fermented mulberry whey beverages ranged from 20.60 to $94.40 \%$ at time zero. Where, DPPH radical scavenging activities were ranged from 7.80 to $50.40 \%$ after 21 days. These results are in agreement with Kim et al. ${ }^{19}$ and Wang et al. ${ }^{36}$ who they reported that fermented Noni juice exhibited lower antioxidant activity, reducing activity, and DPPH scavenging effect compared with unfermented Noni juice. A positive correlation was found between TPC and DPPH radical scavenging activity ( $\mathrm{r}=0.956$, $P<0.05)$.

\section{Sensory evaluation}

Sensory evaluation of mulberry whey beverages prepared with 25.0, $50.0,75.0$ and $100.0 \% \mathrm{BM}$ juices during cold storage are shown in Figure 5 . The mulberry whey beverages prepared with $75.0 \%$ mulberry juice (SWBM3) gained the highest score for color, appearance, and flavor at zero time (Fresh) of storage and after 21 days of storage at 4 $\pm 1^{\circ} \mathrm{C}$. Therefore, these samples came in the first order on comparison with other prepared beverages (SW, SWBM1, SWBM2, and SWBM4) up to 21 days of storage. SWBM3 was the most acceptable sample followed with SWBM2 and SWBM4, while SW and SWBM1 were the lowest acceptable samples since they had been given the lowest scores. Where, all treatments (SWBM2, SWBM3, and SWBM4) kept strong color body and no sedimentation in all treatments. 


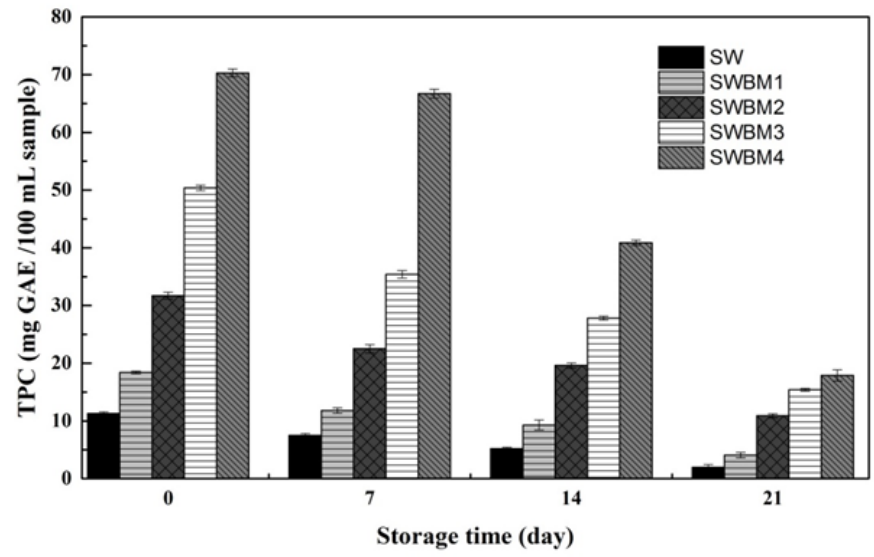

Figure 3 The TPC of black mulberry whey beverages during cold storage at $4 \pm 1^{\circ} \mathrm{C}$.
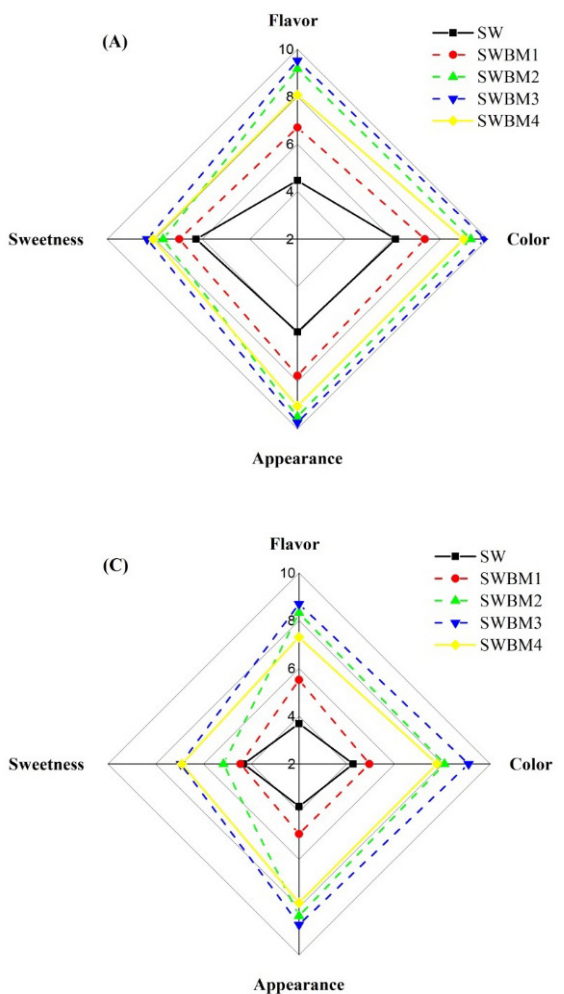

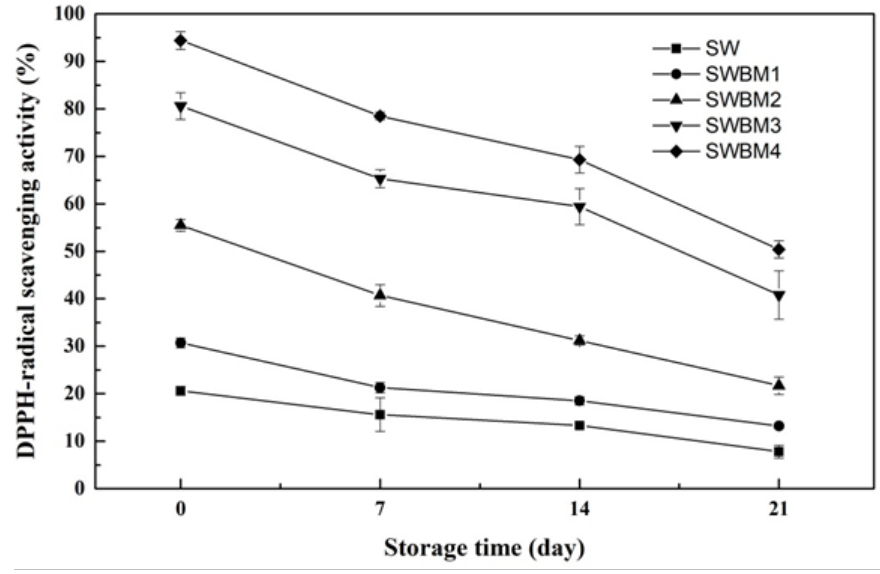

Figure 4 The changes in DPPH radical scavenging activity (\%) of black mulberry whey beverages during cold storage at $4 \pm 1^{\circ} \mathrm{C}$.
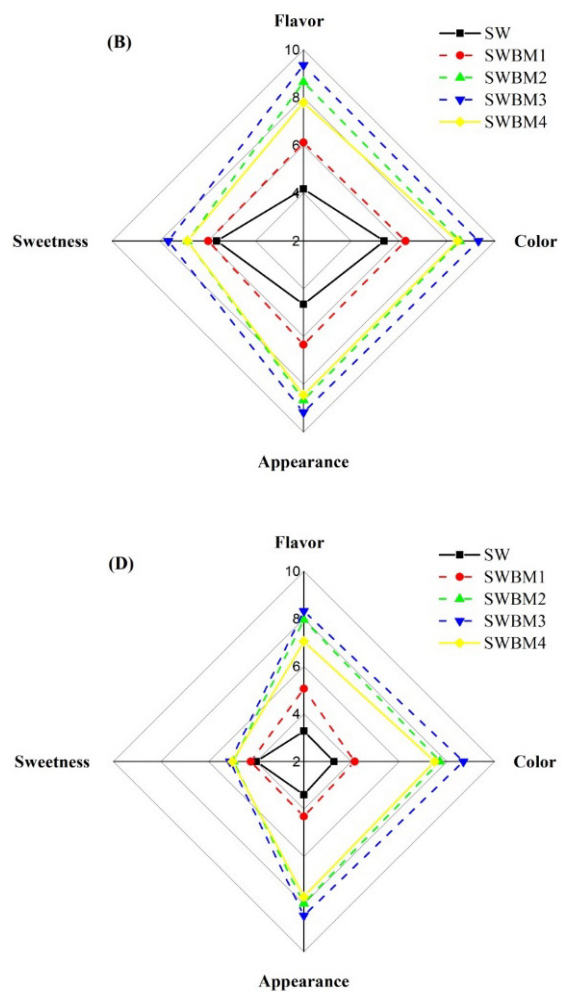

Figure 5 The sensory evaluation of black mulberry whey beverages during cold storage at $4 \pm 1^{\circ} \mathrm{C}$.

\section{Conclusion}

The present study described development of new functional fermented product (mulberry-whey beverage). The results showed that the acidity, antioxidant activity, total phenolic, and anthocyanins contents were increased by increasing the percentage of black mulberry juice. Where, $\mathrm{pH}$ values were decreased. Our results indicated that the viability of L. rhamnosus GG \& Bifidobacterium animalis ssp. lactis $\mathrm{Bb}-12$ remained high up to 14 days then started to decline. SWBM3 samples (25\% whey with $75 \%$ BM juice) gained the highest organoleptic scores. The beneficial effect for the health of black mulberry (anthocyanins), their incorporation in food and beverages industries will represent an extra important value in the near future.

\section{Conflict of interest}

The authors declare no conflict of interest.

\section{References}

1. Gallardo-Escamilla FJ, Kelly AL, Delahunty CM. Influence of starter culture on flavor and headspace volatile profiles of fermented whey and whey produced from fermented milk. J Dairy Sci. 2005;88(11):37453753. 
2. Guimaraes JT, Silva EK, Costa ALR, et al. Manufacturing a prebiotic whey beverage exploring the influence of degree of inulin polymerization. Food Hydrocoll. 2018;77:787-795.

3. Siso MG. The biotechnological utilization of cheese whey: a review. Bioresour Technol. 1996;57(1):1-11.

4. Gallardo-Escamilla FJ, Kelly AL, Delahunty CM. Mouthfeel and flavour of fermented whey with added hydrocolloids. Int Dairy J. 2007;17(4):308-315.

5. Kerry RG, Patra JK, Gouda S, Park Y, Shin H-S, Das G. Benefaction of probiotics for human health: A review. J Food Drug Anal. 2018.

6. Oliveira MN, Sodini I, Remeuf F, Corrieu G. Effect of milk supplementation and culture composition on acidification, textural properties and microbiological stability of fermented milks containing probiotic bacteria. Int Dairy J. 2001;11(11-12):935-942.

7. Koh WY, Uthumporn U, Rosma A, Irfan AR, Park YH. Optimization of a fermented pumpkin-based beverage to improve Lactobacillus mali survival and $\alpha$-glucosidase inhibitory activity: A response surface methodology approach. Food Sci Hum Wellness. 2018;7(1):57-70.

8. Marsh AJ, Hill C, Ross RP, Cotter PD. Fermented beverages with healthpromoting potential: past and future perspectives. Trends Food Sci Technol. 2014;38(2):113-124.

9. Suomalainen T, Lagström H, Mättö J, et al. Influence of whey-based fruit juice containing Lactobacillus rhamnosus on intestinal well-being and humoral immune response in healthy adults. LWT - Food Sci Technol. 2006;39(7):788-795. doi:10.1016/j.lwt.2005.05.012

10. Bertrand-Harb C, Ivanova IV, Dalgalarrondo M, Haertllé T. Evolution of $\beta$-lactoglobulin and $\alpha$-lactalbumin content during yoghurt fermentation. Int Dairy J. 2003;13(1):39-45.

11. Pescuma M, Hébert EM, Mozzi F, de Valdez GF. Whey fermentation by thermophilic lactic acid bacteria: Evolution of carbohydrates and protein content. Food Microbiol. 2008;25(3):442-451.

12. Pescuma M, Hébert EM, Dalgalarrondo $M$, et al. Effect of Exopolysaccharides on the Hydrolysis of $\beta$-Lactoglobulin by Lactobacillus acidophilus CRL 636 in an in Vitro Gastric/Pancreatic System. J Agric Food Chem. 2009;57(12):5571-5577.

13. Pescuma M, Hébert EM, Mozzi F, Valdez GF de. Hydrolysis of whey proteins by Lactobacillus acidophilus, Streptococcus thermophilus and Lactobacillus delbrueckii ssp. bulgaricus grown in a chemically defined medium. J Appl Microbiol. 2007;103(5):1738-1746.

14. Chen P-N, Chu S-C, Chiou H-L, Kuo W-H, Chiang C-L, Hsieh Y-S Mulberry anthocyanins, cyanidin 3-rutinoside and cyanidin 3-glucoside, exhibited an inhibitory effect on the migration and invasion of a human lung cancer cell line. Cancer Lett. 2006;235(2):248-259.

15. Li Y, Zhang X, Liang C, Hu J, Yu Z. Safety evaluation of mulberry leaf extract: Acute, subacute toxicity and genotoxicity studies. Regul Toxicol Pharmacol. 2018;95:220-226.

16. Lin J-Y, Tang C-Y. Determination of total phenolic and flavonoid contents in selected fruits and vegetables, as well as their stimulatory effects on mouse splenocyte proliferation. Food Chem. 2007;101(1):140-147.

17. You Y, Liang C, Han X, et al. Mulberry anthocyanins, cyanidin 3-glucoside and cyanidin 3-rutinoside, increase the quantity of mitochondria during brown adipogenesis. J Funct Foods. 2017;36:348-356. doi:10.1016/j. jff.2017.07.007

18. Hu X-Q, Jiang L, Zhang J-G, Deng W, Wang H-L, Wei Z-J. Quantitative determination of 1-deoxynojirimycin in mulberry leaves from 132 varieties. Ind Crops Prod. 2013;49:782-784.
19. Kim SB, Chang BY, Jo YH, et al. Macrophage activating activity of pyrrole alkaloids from Morus alba fruits. $J$ Ethnopharmacol. 2013;145(1):393-396.

20. Veberic R, Slatnar A, Bizjak J, Stampar F, Mikulic-Petkovsek M. Anthocyanin composition of different wild and cultivated berry species. LWT - Food Sci Technol. 2015;60(1):509-517. doi:10.1016/j. lwt.2014.08.033

21. Cruz AG, Castro WF, Faria JA, et al. Glucose oxidase: A potential option to decrease the oxidative stress in stirred probiotic yogurt. LWT-Food Sci Technol. 2012;47(2):512-515.

22. AOAC. Methods of Analysis. 18th ed. Gaithersburg, Maryland: Association of Official Analytical Chemists; 2006.

23. AOAC. Methods of Analysis. 15th ed. Washington: Association of Official Analytical Chemists; 1990.

24. IDF. Milk-determination of Nitrogen Content (Kjeldahl Method). Int Dairy Fed IDF Bruss Belg. 1993.

25. IDF. Milk-determination of Fat Content. Int Dairy Fed IDF Bruss Belg. 1996.

26. López-García G, Cilla A, Barberá R, Alegría A. Protective effect of antioxidants contained in milk-based fruit beverages against sterol oxidation products. J Funct Foods. 2017;30:81-89.

27. Klopotek Y, Otto K, Böhm V. Processing strawberries to different products alters contents of vitamin $\mathrm{C}$, total phenolics, total anthocyanins, and antioxidant capacity. J Agric Food Chem. 2005;53(14):5640-5646.

28. Dubost NJ, Shewfelt RL, Eitenmiller RR. Consumer acceptability, sensory and instrumental analysis of peanut soy spreads. J Food Qual. 2003;26(1):27-42.

29. Sheehan VM, Ross P, Fitzgerald GF. Assessing the acid tolerance and the technological robustness of probiotic cultures for fortification in fruit juices. Innov Food Sci Emerg Technol. 2007;8(2):279-284.

30. Crittenden RG, Morris LF, Harvey ML, Tran LT, Mitchell HL, Playne MJ. Selection of a Bifidobacterium strain to complement resistant starch in a synbiotic yoghurt. J Appl Microbiol. 2001;90(2):268-278.

31. Matsumoto M, Ohishi H, Benno Y. H+-ATPase activity in Bifidobacterium with special reference to acid tolerance. Int $J$ Food Microbiol. 2004;93(1):109-113.

32. Viljanen K, Heiniö R-L, Juvonen R, Kössö T, Puupponen-Pimiä R. Relation of sensory perception with chemical composition of bioprocessed lingonberry. Food Chem. 2014;157:148-156. doi:10.1016/j. foodchem.2014.02.030

33. Chung C, Rojanasasithara T, Mutilangi W, McClements DJ. Enhanced stability of anthocyanin-based color in model beverage systems through whey protein isolate complexation. Food Res Int. 2015;76:761-768.

34. Castaneda-Ovando A, de Lourdes Pacheco-Hernández M, PáezHernández ME, Rodríguez JA, Galán-Vidal CA. Chemical studies of anthocyanins: A review. Food Chem. 2009;113(4):859-871.

35. Sagdic O, Ozturk I, Cankurt H, Tornuk F. Interaction between some phenolic compounds and probiotic bacterium in functional ice cream production. Food Bioprocess Technol. 2012;5(8):2964-2971.

36. Wang C, Liu Q, Yang WZ, et al. Effects of selenium yeast on rumen fermentation, lactation performance and feed digestibilities in lactating dairy cows. Livest Sci. 2009;126(1):239-244. doi:10.1016/j. livsci.2009.07.005 